\title{
LA ABUELA OSEJO: UN ARQUETIPO DE LA DEA-MATER, INSCRITA EN UNA HIEROFANÍA SELÉNICO-TELÚRICA. A PROPÓSITO DEL LIBRO DE LOS GOZOS DE CARLOS VILLALOBOS VILLALOBOS
}

\author{
Kattia Chinchilla Sánchez
}

\begin{abstract}
RESUMEN
En este artículo, la autora realiza un análisis mítico de la figura de la Abuela Clemencia Osejo, un personaje de El libro de los Gozos de Carlos Villalobos, y la inscribe como un arquetipo de la Dea Mater, que se presenta como la divinidad de un culto iniciático. A partir de este análisis, la autora concluye que la Abuela Osejo se manifiesta como una hierofanía selénico-telúrica.
\end{abstract}

ABSTRACT

In this article, the author performs a mythic analysis of the figure of the Grandmother Clemencia Osejo, a charater in El libro de los Gozos [The book of the Gozos] by Carlos Villalobos, as written as an archetype of the Goddess Mother, which presents herself as the dvinity of a secret sect. At the end of this analysis, the author concludes that the Grandmother Osejo manifests herself as a priestess of the Eleusian rites of the moon and the earth.

En la mentalidad del hombre de todos los tiempos, hay una esfera afectiva -definida, dicotómica y deslindable- a la cual llamamos "lo sagrado". Allí son ubicados los seres míticos (dioses, semi-dioses, héroes, monstruos, grifos), quienes, por lo tanto, participan del fenómeno de lo sagrado: atraen y repelen a la vez (mysterium tremendum et fascinans); son lo otro, lo radicalmente diferente (ganz andere), el tabú, lo maculado, lo valioso, lo valedero, lo auténtico, lo que está cargado de "ser"; en suma, lo sagrado es sinónimo de lo inefable. Cuando consideramos la sacralidad de cara a las manifestaciones culturales, entre ellas la literatura, con altísima frecuencia hallamos allí esta manera de enfrentar el cosmos.

En la novela del filólogo y escritor costarricense Carlos Villalobos Villalobos, El libro de los Gozos, se yergue ante nuestros ojos la figura de la Abuela Clemencia Osejo, viuda de Ortuño, como la Profetisa de Santa Lucía -el pueblo ficcional-, quien ostenta las características anotadas supra con respecto a lo sagrado y más.

Con base en la metodología para la historia de las religiones de Mircea Eliade, la Abuela es una hierofanía selénico-telúrica y, según la teoría de los arquetipos de la psicología profunda de Carl Gustav Jung, Clemencia Osejo es una DEA-TELLUS-MATER. En resumidas cuentas, ambos pilares teóricos nos llevan a un mismo puerto: esta Gran Diosa Madre (tierra y luna, a la vez), presente en las más variadas mitologías del orbe, centraliza y gobierna un 
universo narrativo y, además, es divinidad de un culto iniciático, que, eso sí, particulariza el mito escatológico cuando su líder Juanelí (hierofante, mystes y psicopompo), nieto de la augusta Clemencia, advierte de la proximidad del fin del mundo, que, a la postre, será el suyo propio, en una suerte de apoteosis, al mejor estilo de Joseph Campbell (en El héroe de las mil caras) o en una especie de destino ascético, muy común entre los primeros santos de la cristiandad.

\section{La Abuela, una hierofanía}

Juanelí, el nieto, posee un culto post-modernista cuya deidad conjunta es la Abuela, la Profeta. Ella es la esencia de esta "religión" (nominada clemenciana): es el ente divinizado y electo por la divinidad tradicional (el Dios judeo-cristiano):

...¿quién es esa fuerza? ¿Quién es ese aliento que nos hará seguir hasta la muerte? ¿Quién? ¿Quién es? Muy

bien, hermanos, la Profeta Osejo. Ustedes lo han dicho; la Profeta Osejo, mi Abuela (Villalobos 2001: 64).

Tomando como inicio de esta disquisición la definición de lo sagrado, Clemencia está mancillada, tabuada, en esencia, particularizada. A lo largo del texto, ella transcurre por un devenir que la convierte en una "vegetación viviente y caminante", mas este rasgo, lejos de aislarla, la concentra, inclusive más allá de su deceso, pues es un ser mítico, imponderable y eterno. Al ser ella, en términos de Eliade, una hierofanía, es decir, una mostración de lo sagrado, totaliza y amalgama el espacio circundante, que desde ahora será "espacio sagrado", mediante la conjunción del axis mundi y del simbolismo del centro:

Estaba en el santuario de la Matriarca (...) Dios había escogido aquel lugar como la Meca clemenciana (105).

La novela no nos pone a rivalizar con la divinidad tradicional, antes bien, asume a la Abuela Profeta como una elegida y, asimismo, como una deidad más que es capaz de prodigar en los hombres el bien y el mal. Entiéndase aquí que el homo religiosus ha sido capaz de "divinizar" a esta mujer, puesto que ella misma entroniza lo sagrado:

\footnotetext{
Hermanos, dejen actuar en su corazón el mensaje de Abuela la Profeta, dejen actuar en sus vidas estas palabras. Si la dejaran actuar, aunque sea solamente, digamos quince años nada más para probar, estoy seguro que grandes maravillas ocurrirán. Dejen actuar a la Abuela. Ábranle el Corazón (126).

... voy a revelarle un pasaje de la vida trascendental de esa mujer consagrada a la que el Poderoso ha elegido como su nueva representante en la tierra. Me refiero desde luego a Santa Clemencia, a la matriarca de la Iglesia Clemenciana (145).
}

Por tanto, Clemencia Osejo es una hierofanía, la Mater divinizada, centro de este rito clemenciano; es decir, es un tipo de culto de la Gran Madre, porque más fuerte que el concepto de madre, es la idea de la Abuela; en términos simples, la doblemente madre:

DIOSA-MUJER-MADRE-ABUELA = CLEMENCIA OSEJO 


\section{La Abuela, una hierofanía telúrica}

Las hierofanías de la tierra se caracterizan por su maternidad y, colateralmente, por la fertilidad, por la protección, por la dispensa de los bienes. Una diosa telúrica es mostrada en las mitologías como la gran dadora de la vida, de los alimentos, de la descendencia. Sin embargo, amén de la coincidentia oppositorum, que se haya dentro de la estructura profunda de toda deidad, sus contrarios deben ser tomados en cuenta: esterilidad, maldad, subyugación, entre otros. Es decir, si Clemencia Osejo es una Dea Mater, puede limitar las bondades y las providencias dadas a los hombres, a pesar de que no se manifiesta en el texto como una Kali india, capaz de desintegrar a la raza humana, capaz de fragmentar su propia unicidad, capaz de masacrar al género humano, capaz de lo más negativo que podamos imaginar, dentro del marco de la "maternidad negativa". En una sola palabra, es la Deméter eleusinia:

\footnotetext{
... por la audacia de Abuela la Profeta y su habilidad milagrosa de hacer que una misma olla apenas alcanzara para dos personas o bastara y sobrara para alimentar a un ejército (15).
}

La Abuela, Mater Tellus, multiplica o limita los bienes alimenticios, en acto casi mágico, el cual deviene de su infalible virtud de dominar los misterios de la fecundidad. En este sentido, a partir de una curiosa relación biunívoca entre hombre y deidades, ya satirizada desde el siglo décimonónico por Niezstche en Así hablaba Zaratustra, se recibirá de la Dea Mater lo equitativo dentro del marco de las normas rituales: dar para receptar:

\footnotetext{
... hay que entregar ayudas para la obra de la Profeta. Por eso den, den y el fantasma de mi Abuela, hermanos, el espíritu de mi Abuela, les devolverá siete veces (80).
}

Tomando lo precedente para la próxima reflexión, un plato nutricio otorgado por la diosa constitúyese en un don más allá de lo delicioso, con la singular facultad de brindar la vida nuevamente ("resucitar"). Recordemos aquí la vid, dada por Dionisos; el cereal o el trigo, donado por Deméter; el vino y el pan, ofrendado por Jesús. Ahora bien, la comida en cuestión es la folklórica olla de carne, la cual es elaborada, en parte, a base de verduras múltiples, cosa que la hace muy semejante al "satur" de los romanos, compuesto de las más variadas especies comestibles, a propósito de las saturnalia, en la que festejaban el tránsito de la estación de la muerte a la del renacimiento primaveral. En nuestro caso, la Abuela Profeta, experta en "ollaecarnes", disemina la re-generación entre sus comensales, lo cual recuerda, mutatis mutandi, ese acto único de la deidad que es devorada para la resurrección. No olvidemos que en el esquema tradicional de la mujer-ama de casa, el nexo de la madre como especial dadora del alimento revigorizante es inevitable, incluso desde el alba del ser humano en su fase lactante:

\footnotetext{
Y todavía, hermanos, Abuela y yo vivíamos en la vieja casona de los grandes milagros (...) llegaron muchos viajeros (...) sobre todo, venían a comer las exóticas ollecarnes (sic) que solo Abuela sabía preparar. Una vez satisfechos reposaban tres días y tres noches (...) todos quedaban como resucitados, y por eso la anciana era conocida por aquel entonces como la Resucitadora de Santalucía (11).
}

Dentro del contexto extático de las religiones mistéricas, como lo refiere Ioan Couliano, luego de saciar las necesidades del comer y del beber, buscábase la trascendencia del alma (éxtasis) mediante una orgía sin igual. Vemos en el texto de Villalobos estos singulares aspectos 
de lo que implica una iniciación orgiástica, a partir de un banquete, notoriedad ligada a los cultos de Misterios, cuya deidad central era una hierofanía selénico-telúrica (Dionisos, Deméter, Cibeles, Isis):

Pero eso sí, hermanos, en cuanto olían la famosa receta de carne con verduras -yuca, nampí, chayote y ta-
cacos- que preparaba Abuela la Profeta, les entraba una tentación del carajo (...) Había que verlos hartán-
dose y chupándose los dedos en un éxtasis, (...) hubiera pensado que eran posesiones leviatánicas (12).

Dos pulsiones han sido saciadas: la alimentación y la sexualidad. ¿Será por esto que nuestro texto en cuestión se advoca Libro de los gozos? Gozos a partir del éxtasis de lo comestible y de la orgía, dentro de una religión clemenciana, cuya matriarca es una Dea Mater... Creemos que es hilar muy delgado, pero la interrogante se mantiene.

Como es de suponer, no se concibe una diosa de la tierra sin voluminosos pechos, que expliciten la fertilidad, que muestren el poder de lo femenino a través de un órgano cautivante e intimidador hacia el sexo masculino. Grandes senos, casi monstruosos, son sinónimos de la ancestral vagina dentata del mundo rupestre, en donde la ferocidad de la maternidad está de manifiesto. No olvidemos, nuevamente, sobre este punto la coincidentia oppositorum. La Abuela Osejo ostenta sus mamas y, en cierta medida, nos recuerda a las antiguas sacerdotisas (profetisas) del mundo minoico: sosteniendo una serpiente en cada brazo, sus abundantes pechos están desnudos:

Hay que tener un corazón blando (...) ojalá más grande que los senos de mi Abuela la Profeta (15).

Que los grandes senos de la Abuela la Profeta, te llenen siempre de gozo (18).

Benditos sean los grandes senos de mi Abuela, hermanos. Benditos sean, Benditos (sic) sean, Beeenditos seean (sic), hermanos (39-40).

( ...) para la gloria de los grandes senos de la profetisa Osejo, la última matriarca de la Historia (51).

Los senos no sólo implican la maternidad nutricia de la tierra, sino que también son símbolos de la hierofanía selénica -segunda parte de esta presentación de la Abuela Osejo-. Por ejemplo, entre los egipcios, el jeroglifo "mena" significa busto y a la vez luna. Muchas traducciones nos hablan de la Gran Diosa, alimentadora del mundo, como iconográficamente fue representada la Artemisa de Éfeso, con sus incontables hileras de pechos. En la mayoría de los idiomas "Ma-Ma", que se usa para nominar a las madres o Abuelas, atiende, según Potter, a la Madre de los Pechos y su forma estética nos remite inevitablemente a la luna llena. Como curiosidad, en la antigua Roma, el proceso de instrucción era considerado como una vuelta a la segunda infancia; de ahí la frase "alma mater", el alma de la madre, sacerdotisa y educadora, nominación docta para todas las universidades del mundo, y, asimismo, "alumnus", en alusión a los educandos que son sus hijos lactantes.

Volviendo a lo nuestro, Clemencia Osejo es telúrica y selénica a la vez, a propósito de sus enormes pechos: senos telúricos, considerando que incluso las montañas son vistas como los senos de la Diosa Madre (cfr. con Gea en el Monte Olimpo), y mamas selénicas, tomando en cuenta su obvia morfología, similar a la luna llena y a partir de la leche, cuyo simbolismo está supeditado a la extensa cadena del agua, que está regida por la ley universal del devenir 
cíclico. Ahora bien, la Abuela Osejo es la Profetisa amén de sus marcados rasgos telúricos, como Diosa Madre, y selénicos, como los veremos más adelante; es decir, es Profeta por su sabiduría infinita proveniente de los símbolos que hacen de ella una hierofanía de la tierra y de la luna a la vez: conoce todos los secretos de la tierra, de la fertilidad, en suma, de la vida, la muerte y el renacimiento.

Mircea Eliade hace énfasis en que la hierofanías telúricas son las “dueñas del lugar”, capaces de albergar la totalidad de las otras mostraciones de lo sagrado. Pero en cuanto al imperio de los espacios, las deidades de la tierra son radicales (cfr. la leyenda del Volcán Rincón de la Vieja). Clemencia es la casa, es el espacio sagrado cuyo centro es ella misma:

Salid todos de esta casa, porque esta casa es el espacio de mi cuerpo. Alejaos todos de este sitio, porque este sitio es el sitio de mi sangre (13. Habla la Abuela Osejo).

Resulta muy curioso que la Abuela Osejo se traslade de morada a un barrio cuyo nombre es aún más sugerente: el Bajo de los Guindos. Leemos aquí la zona cacactónica, el mundo infraterrestre cuya tutela debe estar asignada sólo a una hierofanía telúrica, pues la tierra va más allá de sí misma, amén de su zona infernal (cfr. Deméter-Perséfone):

(...) se iría definitivamente a vivir al bajo de los Guindos, donde vivían cuatro de sus hijas. Decidió que iba a abandonar de una vez por todas aquel lugar (...) Aquella decisión de Abuela debe ser interpretada como un llamado a la transformación (41).

Aquí, retomemos su rol profético: es sabia, conoce todas las instancias del cosmos, lo supraterrestre y lo infraterreste, las zonas en donde se conjugan las arcanas fuerzas de la vida, la muerte y el renacimiento, en especial cuando consideramos, por ejemplo, el destino vegetal. A partir del paradigma metodológico de Jung, el arquetipo de la madre contempla la sabiduría absoluta en su forma simbólica de la "Abuela", la madre-mujer-anciana sabia, visionaria de lo que habrá de acontecer (cfr. con el "sexto sentido" de las madres):

Aquí nació una Profetisa, la última de todos los tiempos. Me refiero a Clemencia Osejo, viuda de Ortuño.

Y nació también un Elegido, que la proclamó y la proclama: su nieto Juanelí... (23).

Desesperados decidieron venir hasta Santalucía para consultarle a mi Abuela, que ya era como un faro de luz para los hombres de la tierra (15).

\section{La Abuela, una hierofanía selénica}

La gerencia oracular se entiende a partir de la combinación de un centro de adoración y consejería, un espacio sagrado, un vocalista de la fortuna, una escuela de profetas, un formador de opinión, un dispensador de consejos médicos y políticos y un punto de enlace entre lo humano y lo divino. Varios de estos elementos están esbozados en la Profeta Osejo, siendo la "matriarca" asunto de alta relevancia, pues estas prácticas oraculares fueron regidas por diosas maternas (de la tierra y de la luna al mismo tiempo) (cfr. Gea en Delfos y su suplantación por Apolo). Es decir, in illo tempore, las funciones proféticas fueron llevadas a cabo por mujeres, con sus consecuentes prácticas colaterales: adivinación, medicina (curandería), rituales 
del éxtasis. En su rol soteriológico, la Profeta Clemencia (sugestivo nombre) es la intercesora, la salvadora, la curandera chamánica:

Sálvame, Santa Hacedora de prodigios. Sálvame, Resucitadora de Santa Lucía. Sálvame, Hacedora de ollecarnes. Sálvame, Inmaculada Curandera (26).

En el arquetipo de la madre existe una derivación simbólica que atiende a la bruja-hechicera-hacedora de milagros:

\section{PROFETA OSEJO: MADRE-ABUELA-BRUJA-CHAMÁN}

La Abuela posee objetos mágicos, es decir, de las transformaciones, los cuales están regidos por la ley del devenir cíclico de la luna, a partir del tránsito transformador de su propia apariencia (fases). Los artículos mágicos poseen el fascinante don de transmutar los estadios y nuestra Abuela los ostenta y los ciuda con esmero:

(...) la Profetisa alistó maletas: guardó bien sus vestidos carmelos con todo y escapularios y rosarios. No olvidó, desde luego, los frascos de las milagrosas sustancias, unas cartas de Tarot español, los ungüentos antirreumáticos, la güija y todos los demás tiliches (43).

No olvidemos que el conocimiento con base en las hierbas, muy propio de todas las Abuelas a lo largo y ancho del planeta, responde a un símbolo selénico marcado: las plantas son gobernadas por el arbitrio de la luna, desde su ciclo de vida-muerte-renacimiento:

... con el único propósito de ser recuperados por las curaciones de mi Abuela la profeta, quien a punta de yerbas hacía milagros (13).

Clemencia Osejo es hacedora de hechizos, es bruja, pero carente de las connotaciones negativas que el lexema conlleva a veces. Huelga decir que el texto es irónico en este sentido, pues la Abuela con frecuencia fracasa en su ánimo de prestar ayuda sobrenatural:

\footnotetext{
... Abuela hizo un triángulo con una vela en cada extremo de modo que la vela no marcada apuntaba al norte, la vela de Juan al oeste y la vela de Duliana al este. Después la vieja puso la foto en el centro del triángulo y encendió las tres velas, empezando por la del norte y acabando por la del oeste.

Acto seguido, hermanos, Abuela oró con todo fervor y se persignó siete veces. Cerró los ojos y encomendó sus padresnuestros apuntando hacia arriba, más allá del tizne de la chimenea, más allá del árbol de jocote, más allá, hermanos, de los pecados del mundo (27).
}

Este remedio amatorio fracasa por la muerte de Juan, quien no consigue la atención de Duliana. En otra oportunidad, la Abuela logra establecer una relación cosmobiólogica de interés cuando su nieto se hallaba en peligro:

Entonces la anciana encendió tres culitos de candela a San Martín de Porras y puso debajo de la cama, en una lata de manteca, una imagen de la Virgen de la santa Inquisición.

Estoy seguro que este acto me salvó, no me cabe la menor duda, hermanos, sobre todo lo de la Virgen, pues fue como si estuviera embadurnado de manteca. Me le resbalé al tipo y he aquí que fue un milagro que saliera vivo de tal aventura (56). 
Nótese la combinación entre los rezos tradicionales de la religión católica y los ritos heterodoxos, más comunes en el marco de la santería antillana. Veamos este otro ejemplo:

Sacó un nido de macuá que había pertenecido al abuelo, encendió una velita a San Antonio y le puso un poco de masa de arracache alrededor (90).

Aquí se produjo un efecto erótico en todas las mujeres que rodeaban a Juanelí y sus primos, lo cual evidencia la siguiente estructura:

\section{HECHIZO - SEXO - FUROR - ATADURA: DIOSA CTÓNICO-SELÉNICA}

Las ataduras, los lazos o los nudos son propios del mundo infraterrestre, simbólicamente hablando, cual raíces aglutinantes. El nido de macuá (panyptila cayennensis) es utilizado para embrujos en las zonas rurales del Valle Central de nuestro país y tiene un enlace con lo erótico, por supuestos poderes afrodisíacos. Recordemos, sólo por curiosidad, que San Antonio "repara", es decir, brinda o prodiga lo que hace falta; de ahí el uso que se le da a su efigie en varios países de América Latina para que "repare" novio a las solteronas.

La Abuela posee el vicio de fumar puros, rasgo conspicuo entre los chamanes de diversas culturas, pues el humo establece un axis mundi entre el cielo y la tierra y, además, puede ser considerado como ritual extático cuando su picadura no es de tabaco. Este vicio ubica a la Abuela en lo selénico y lo telúrico a la vez:

\footnotetext{
... Abuela la Profeta debe estar con Él fumándose un puro sagrado, de esos que seguramente tienen en los reinos de la abundancia (20).
}

Finalmente, en lo atinente a su papel selénico, observamos una inversión de la jerarquía y de las formas (mostración carnavalesca) encuadrada en una regeneración. Es decir, la locura de la Abuela, quien aparece a los tres días de muerta, es una forma más de lo lunar:

\footnotetext{
A los tres días Abuela apareció de nuevo. Pero esta vez, venía con un extraño traje de bailarina andaluza y en vez de echarnos una bendición bailó al compás de un extravagante ritmo místico... (183).

... soy la esposa de Morgan. (...) Entonces, hermanos, supimos, lo que había pasado: el espíritu de Abuela se había vuelto loco (184).
}

\section{Conclusión: la Abuela, hierofanía vegetal}

Una vez que hemos apreciado cómo la Abuela Profeta es una hierofanía telúrica y selénica, inscrita en el arquetipo de la madre, la novela nos marca un nexo vegetal que refunde lo anterior a una sola sintaxis: la hierofanía vegetal, unión de la tierra y la luna. La vegetación es nacida de la matriz de la tierra y regida por períodos precisos (las estaciones), los cuales hacen que nazca, muera y renazca eternamente. Su cuerpo es ya el paisaje, la totalidad de hierofanías, que Eliade resalta como atributo de la tellus, pero que, en definitiva, lo sintetiza mejor lo vegetal. Por lo tanto, la Abuela Profeta Clemencia Osejo, viuda de Ortuño, es, sin temor a equivocarnos, una hierofanía selénico-telúrico-vegetal: 


\begin{abstract}
Y aconteció por aquel entonces que, luego de la Navidad, a Abuela le empezaron a salir unos extraños musgos en las axilas. Primero parecían lunares amarillos y luego en lugar de vellos le fueron creciendo plantas verdosas. Al principio eran formaciones más grandes que los hongos, como líquenes de esos que se forman en los madroños caídos (148).

... cuando una tarde un yigüirro se posó en el hombro de Abuela la Profeta, y sin más ni más decidió hacer nido ahí mismo. Removió los vellos verdosos de la anciana, trajo ramas y hojas secas, e inició su labor. Cuando la vieja se despertó trató de espantar el pajarraco, pero fue inútil: el animal defendió su territorio a picotazo limpio (149).
\end{abstract}

Para acabar nuestra disertación, curiosamente encontramos esta cita:

Ella no sabía, hermanos, que en el espíritu de mi Abuela mora Astarot y Asera (176).

Tradicionalmente, Astarot preside el Occidente y se le invoca los miércoles. Tiene la figura de un ángel muy feo, igual que Hades. Es el gran tesorero y da buenos consejos cuando se ponen a su dictamen nuevas leyes. Con su catalejo, conoce el pasado, el presente y el futuro. No obstante, según ciertos estudiosos, tanto Astarot como Asera -y otros epítetos másson variantes de la Gran Madre que los antiguos cananeos adoraron libremente, en un período anterior a la imposición monoteísta. Con el correr del tiempo, hubo un proceso de transformación y dichos apelativos fueron endosados a Satanás y a la Bestia apocalíptica (cfr. Is. 65, 11-12 y Ez. 8, 3). En cuanto a lo que nos interesa, la Abuela Osejo encarna una vez más, en esos nombres, a la Gran Diosa Madre, con connotaciones telúricas, selénicas y vegetales.

\title{
Bibliografía
}

Couliano, Ioan P. 1994. Experiencias del éxtasis. Barcelona: Paidós.

Chevalier, Jean. 1988. Diccionario de los símbolos. Barcelona: Herder.

Chinchilla Sánchez, Kattia. 1993. "Deméter: una diosa de estrato telúrico”. Revista Káñina. XVII (2): 233-44.

1995. "Deméter-Perséfone: el binomio integrador de planos y ciclos cósmicos". Revista Káñina. XIX (2): 41-7.

1995. "Perséfone: una diosa de sustrato ctónico". Revista Káñina. XIX (1): 143-51.

1997. "El principio del mal en el pensamiento cristiano: Análisis mítico-simbólico de la figura de Satanás”. Revista Káñina. XXI (2): 151-63.

Eliade, Mircea. 1978. Tratado de historia de las religiones. Madrid: Cristiandad.

Getty, Adele. 1990. Goddess. London: Thames and Hudson. 
Jung, Carl Gustav. 1971. El hombre y sus símbolos. Madrid: Aguilar.

Progoff, Ira. 1967. La psicología de C.G. Jung y su significación social. Buenos Aires: Paidós.

Quesada Pacheco, Miguel Ángel. 1991. Nuevo diccionario de costarriqueñismos. Costa Rica: Ed. Tecnológica de Costa Rica.

Sagne, Cécile. 1992. El erotismo sagrado. México: Gali.

Sagrada Biblia. 1957. New York: Grolier.

Villalobos Villalobos, Carlos. 2001. El Libro de los Gozos. San José: Editorial San Judas Tadeo.

Vries, Ad de. 1984. Dictionary of Symbols and Imagery. Netherlands: Elsevier.

Walker, Barbara. 1988. Woman's Dictionary of Symbols and Sacred Objects. San Francisco: Harper Collins Publishers. 